\title{
Blockchain Application in Banking System
}

\author{
Minhaj Uddin Chowdhury, Khairunnahar Suchana, Syed Md Eftekhar Alam, \\ Mohammad Monirujjaman Khan
}

Department of Electrical and Computer Engineering, North South University, Dhaka, Bangladesh

Email: monirujjaman.khan@northsouth.edu, minhaj.uddin17@northsouth.edu, khairunnahar.suchana@northsouth.edu, syed.alam18@northsouth.edu

How to cite this paper: Chowdhury, M.U., Suchana, K., Alam, S.M.E. and Khan, M.M. (2021) Blockchain Application in Banking System. Journal of Software Engineering and Applications, 14, 298-311.

https://doi.org/10.4236/jsea.2021.147018

Received: June 16, 2021

Accepted: July 12, 2021

Published: July 15, 2021

Copyright $\odot 2021$ by author(s) and Scientific Research Publishing Inc. This work is licensed under the Creative Commons Attribution International License (CC BY 4.0).

http://creativecommons.org/licenses/by/4.0/

\begin{abstract}
The $21^{\text {st }}$ Century is all about technology. People are open to accepting new technologies as the need for modernization is increasing every single day. Blockchain is one of those new and revolutionary technologies that will have a significant impact on the market and industry. In layman's terms, Blockchain is a data structure that stores transactional records while also ensuring security, transparency, and decentralization. There is a digital signature on every transaction on a blockchain, which proves the authenticity of the blockchain. In a Blockchain, data is stored which is tamper-proof and cannot be changed as it uses encryption and digital signatures. To change a record on a blockchain, one needs to change several records, and one needs to change the distributed ledger. That's why it's quite impossible to change the data which has already been entered into a Blockchain. The Blockchain is a technology that will allow transactions simply, safely, effectively, and also safely. This is a very promising technology. It's already in a lot of places. It can also solve any problem in the banking sector. This technology became famous after introducing the first cryptocurrency, which is known as bitcoin. Right now, there is a huge problem with banking, and the Blockchain can solve these problems. This paper will demonstrate transacting over a secure, blockchain-based network and therefore eliminate the need for intermediary entities. This paper is a review-based paper that provides the application and opportunities of the Blockchain in the banking system. The purpose of this paper is to provide a review of the application and opportunities of the Blockchain for a secure banking system. In this review investigation and analysis of this paper at the beginning, related work from other authors in the same fields has been discussed. Then the working method of the Blockchain technology has been introduced with analysis. The use of blockchain technology for secure banking has been discussed. The main achievement of this paper is to demonstrate how the Blockchain works and how it can be useful in the secure banking industry.
\end{abstract}




\section{Keywords}

Blockchain, Banking, Immutable Record, Distributed Ledger, Hash, Application

\section{Introduction}

The Blockchain is a new technology that has generated a lot of buzz in recent years. It's almost impossible to talk about recent technologies ignoring the term "Blockchain". A Blockchain is a technology that allows digital data to be stored in a public, shared database. It is essentially nothing more than a series of immutable blocks [1]. All sorts of banking apps can be served with these immutable blocks. Blockchain has the potential to change the banking process to a secure and efficient process which will be a completely transparent procedure compared to these regular processes. This technology is well known as the cryptocurrency (Bitcoin)'s backbone technology. During 2018, it was seen that everywhere, from gaming to banking and everything in between, there were uses of the Blockchain. It was 2017 when the "jump-out-of-the-cake" moment on the Blockchain was held. Nowadays, everywhere and in every tech block, it is seen that Blockchain is mentioned multiple times [2]. It was not known to all before. But recently, as the Blockchain has been showing so much potential, it has become familiar to many people. In almost every sector, people are working so that they can use this amazing technology to solve their problems.

Some people actually believe that banking and blockchains do not belong together. Presently telephones are being used to ask AI-powered chatbots to check our reserve funds, yet that is it. The actual centre of how our fund's work has neglected to stay aware of the $21^{\text {st }}$ Century. Notwithstanding all the tech available to them, monetary controllers actually work precisely equivalent to what they did many years prior. Monetary elements actually have the ability to hinder our exchanges. They pay for endless expenses, gather and keep individual information, and direct the terms of how people utilize their own checks. People have little influence over this game plan, despite the fact that significant resources are allocated to us rather than them. The majority of us are customized to believe that these models are the solitary method of taking care of a lot of cash. Nonetheless, the financial business has been spearheading different options for quite a long time. There have been some astounding accomplishments that came about because of banking patterns over a generally brief timeframe. Nonetheless, testing the central state of affairs demonstrated too large of a hindrance to survive at any rate, up to this point.

Banking may finally have what it takes to make a genuine mark in our traditional monetary areas, thanks to Blockchain. By utilizing this new factor in the monetary condition, banking organizations can utilize the properties of blockchain frameworks to really change how the economy functions [3]. Blockchain 
innovation has shown the possibility to all around reshape the manner in which business executes across essentially every industry in the worldwide economy. As the innovation and its utilization cases proceed to advance and advance, Blockchain is enabling endeavours to drive more noteworthy straightforwardness, detect ability, and operational productivity for a large number of deals and agreements. As a result of its expense-saving advantages, the domain of accounts is Blockchain's essential application post-Bitcoin. Worldwide banking has gotten very costly. At any significant bank, there are a few middle people and outsiders associated with guaranteeing the dependability and security of regular exchanges. Sadly, the expenses of these administrations frequently lay decisively on the shoulders of steadfast clients. Banks are frequently scrutinized as wasteful, costly, and non-straightforward. Neo-banks Fintech like N26, Revolut, PayPal are upsetting conventional keeps money with their creative arrangement. Blockchain proposes answer for these analyses just as gives the upper hand over the Fintech business. Additional time, the interest in Blockchain has developed strongly; furthermore, late national banks and governments have likewise begun investigating its utilization cases. With numerous banks all throughout the planet investigating the capability of Blockchain, the future looks encouraging.

Blockchain alongside AI, mechanical cycle robotization, enormous information, and so on are considered as what's to come innovations. Blockchain has acquired immense consideration from banks, private value firms, new businesses, also, other monetary organizations. The huge banks like Merrill Lynch, J.P Morgan, HSBC, The Bank of America, and numerous others have effectively executed an exchange with Blockchain and are anticipating execute the innovation in their plan of action. The element of blockchain-the decentralized and changelessness record could get the insurgency the record-keeping framework. Blockchain innovation can be utilized in banks and pretty much every business. It can possibly change the backend of the banking framework and decrease huge measures of operational expense. Blockchain would be basic in tackling the current issues in banks. The principal benefits of blockchains are effectiveness, cost decrease, straightforwardness, and disposal of the outsider. First and foremost, Blockchain improves the productivity of exchange as it wipes out the dynamic time. Record keeping and overseeing can be computerized and be finished quicker than labour. Furthermore, it saves the exchange and activity cost. The instalment, what's more, the settlement should be possible without the need of outsider and strong agent charges. Blockchain utilizes cryptography to give the trust of the outsider. At last, blockchains are circulated, which permits the two players with the ongoing data of the exchange and, in this way, prompts straightforwardness.

In recent years, it has been observed that there are many data breaches happening in the banking system. Hackers are stealing vast amounts of money from banks because of the security issue of the banking system. Also, the banking system is improving very slowly. Even in the $21^{\text {st }}$ century, it takes a lot of time, 
sometimes days, to make transactions. The purpose of this paper is to analyze the Blockchain system and find its use cases in the banking system. It will demonstrate why the implementation of the Blockchain can make the banking industry more secure and make transactions faster. The significance of the paper is to help the decision-makers of the banking sector and government to make them understand blockchain technology and it's potentiality in the banking sector.

\section{Related Work}

The Blockchain is a new and advanced technology that is still in its early stages. But as of now, a critical amount of work has been wiped out of this field.

The authors of [4] discuss the conceivable outcomes of utilizing the blockchain in finance and managing the banking sector. The objective was to discover the potential value of the blockchain in the fund and in managing the account segment. The author investigated how the blockchain inquiries about the past. Bitcoin is closing these crevices and a few of the challenges that remain.

In this [5] article, the writer examines the utilization of Blockchain innovation without tokens to ensure data about financial exchange subtleties. The article dissects the assurance components of appropriated data sets, and proposes an answer to the issue of keeping the uniqueness of the data in them dependent on blockchain innovation without tokens. In the end, the author gives proposals for the presentation of Blockchain innovation into current financial frameworks. According to the authors, a blockchain without mining or tokens will significantly improve the cycle of support for the integrity and uniqueness of data on bank exchanges.

The authors of this [6] paper takes a gander at the difficulties and chances of executing blockchain innovation across banking. Blockchain innovation can streamline the worldwide financial framework, accomplishing economical turns of events, utilizing more efficient frameworks than as of now. The authors suggest that utilizing blockchain innovation in financial cycles can be taken care of by conquering the current hindrances of the blockchain, which are found in "bitcoin". These burdens are the high energy consumption and the high cost of the equipment.

In this examination [7], the authors propose the foundational advancement model for breaking down and following the way of development. The model can be connected to any kind of industry to comprehend the cycle of advancement, improvement, and the techniques to win a piece of the pie in the financial business. The investigation findings reveal the circumstances under which most banks compete to develop their own Blockchain banking frameworks. The investigations, in view of the foundational advancement model, likewise show the low fundamental component of Blockchain banking as of now.

This paper [8] talks about the upsides of blockchain innovation for commercial banks from the accompanying viewpoints: charging activity, cross-line installment activity, and the resource securitization business of commercial banks. 
Blockchain innovation has the potential to reduce exchange costs for both parties while also increasing the working proficiency of business banks' and executives' activities.

The authors of this paper [9] analyze blockchain innovation as an innovative development in the financial administration industry. In an assessment dependent on 12 monetary administration suppliers, the authors found that financial administration associations will in general view blockchain advancement as a lower need because of the absence of a method of significant worth. They presume that as ventures face new innovation and development, for example, blockchain, they should think about proficient approaches to investigating and to decide if they can profit from the advancement to be utilized or not.

The primary reason for the paper [10] is to show that blockchain innovation may disturb the current plans of action and to investigate how this may happen. New advancements like the blockchain might be one of the drivers of the plan of action's development. Toward the end of this paper, it is suggested that users ought to follow improvements in this field to plan for potential interruptions in business.

The authors of this paper [11] portray a proposition for the interaction of loaning, checking, and assessing improvement projects in the Brazilian Development Bank utilizing blockchain innovation. The proposal simplifies public cash assignments, improves manual exercises, reduces operational expenses, and generates data to aid in the overall investigation of the benefits arising from the bank's credit. In the wake of featuring the difficulties of carrying out the referenced proposition, this paper likewise talks about what should be possible as a progress cycle utilizing blockchain innovation and blueprints that have effectively been finished.

In this paper [12], the author shows the applications of blockchain technology in crowd funding. Crowd funding is a fundamental utility, particularly for small market ventures, as a new venture amid the unavoidable danger of a business emergency and uncertainty. It is, consequently, fundamental for governments to work with admittance to assets in small endeavors. Despite the ideal climate of the EU, crowd funding has not been exceptionally effective in the area. The steady development of the area further represents that training is a need that business visionaries hope to raise the money to work on. Conventional crowd funding in the EU has been upset by worries about acts of neglect, for example, tax evasion, data deviation, and extortion that prompt authoritative limitations on raising support exercises. By the way, blockchain innovation is a tool that creates a huge desire for the global restoration of crowd funding. Innovation is a progressive and difficult advancement that focuses on the reduction of organizations and guidelines without sacrificing legal arrangements for business advantages. The blockchain innovation provides a convey public record that improves straightforwardness to the point where members can lead endeavors without worrying about inconvenience over the web. Above all, blockchain innovation 
dispenses with data imbalance completely in this way, fitting each partner's requirements for evidence of credibility.

According to a World Bank report from 2014, approximately 2 billion people do not approach the banking administration. India accounts for $20.6 \%$ of the unbanked population. In this [13] paper, the authors talked about how the square chain can assume a huge part in the monetary inclusion measure. They said that FI utilizing blockchain for inner and cross-line installments can bring down costs, abbreviate settlement time, and give a better client experience. They presumed that controllers ought to draw in, intercede at the beginning phase and shape the development.

In this paper [14], the authors have introduced their thoughts by inspecting the Chinese banking area. They said that Blockchains could alter the hidden innovation of the installment clearing and credit data frameworks in banks, in this manner, overhauling and changing them. Blockchain applications likewise advance the arrangement of multi-focus, pitifully middle of the road situations, which will improve the proficiency of financial business. It is significant that during the time spent on each new monetary development, the issues of guidelines, proficiency, and security have consistently sparked a broad discussion. In any case, history isn't halted by current hindrances, as the specialized, administrative, and different issues of blockchain innovation will eventually be settled. Consequently, the possibility of coordinating blockchain innovation into the financial business will undoubtedly happen sooner rather than later.

\section{Working Method}

A Blockchain is a computerized concept for storing data. Figure 1 shows the working method of the blockchain. As information comes in blocks, those squares can be called squares of information. At the point when these squares are bound together, these information blocks become permanent. This implies that when the squares are affixed together, the information can't be changed much. This technology is set apart as a transformation since this innovation permits individuals to keep histories of things, for example, bank balances, cash, properties, characters, clinical records and so forth. Individuals can depend on this innovation as they don't have to fear about anybody altering those records. For instance, assuming users purchase a property and store the property records on a blockchain, they can generally demonstrate that this property is legitimately for themselves. No one will actually want to distort or mess with that record which they put away on a blockchain. That is the reason Blockchain is a progressive innovation which permits individuals to securely store information. Presently, it should be perceived how blockchain really functions in banking.

For every transaction on a blockchain, first it must go through several key steps. From Figure 1 the working method of the blockchain can be observed. For a transaction in the blockchain, and authentication is required, then a block with the information of the transaction is created. Then the created block is sent 


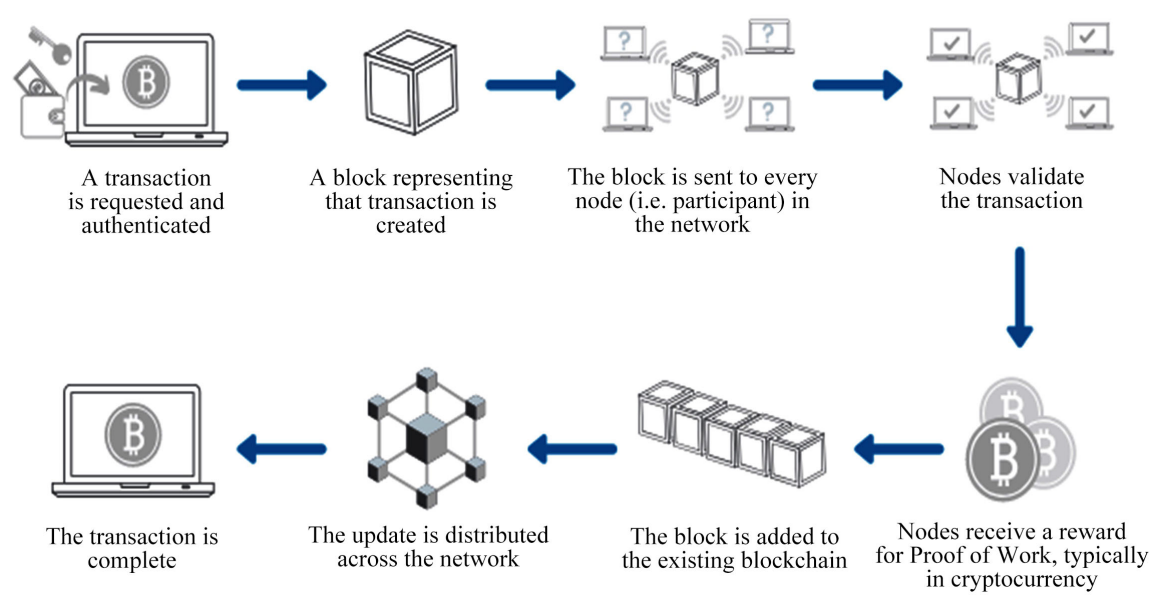

Figure 1. Blockchain working method [15].

to every node or to every participant in a blockchain. Then the nodes validate the transaction. If the information of the newly created node is wrong or altered, then it will not match with other blocks of the nodes in the blockchain. Then the validation will fail, and the transaction will not be recorded. If validation is passed, then the transaction is complete. And the updates will be distributed to all the nodes in that particular blockchain network. And the block is appended to the blockchain. For the Proof of Work, the nodes receive a reward, usually in cryptocurrency.

\subsection{Authentication}

When blockchain was planned, it was intended to work without a focal power. Yet, currently, exchanges should be verified. This validation is finished by utilizing cryptographic keys. Cryptographic keys comprise of two keys and those are Private key and Public key. Every client has their own private key and a public key that everybody can see. At the point when these two keys are utilized, they make a protected advanced character to tie down computerized personality to confirm the client through computerized marks and for opening the exchange they need to perform.

\subsection{Authorization}

At the point when the clients have agreed on the exchange, it should be approved before being added to a square in the chain. The choice to add an exchange to a public blockchain is made by agreement. The arrangement of rules by which a blockchain network works and approves the data in the squares is known as a "agreement". In this way, the exchange should be considered as substantial by dominant part of the hubs or PCs in the organization before added to the blockchain.

\subsection{Proof of Work}

Figure 2 shows proof of work in blockchain technology. 


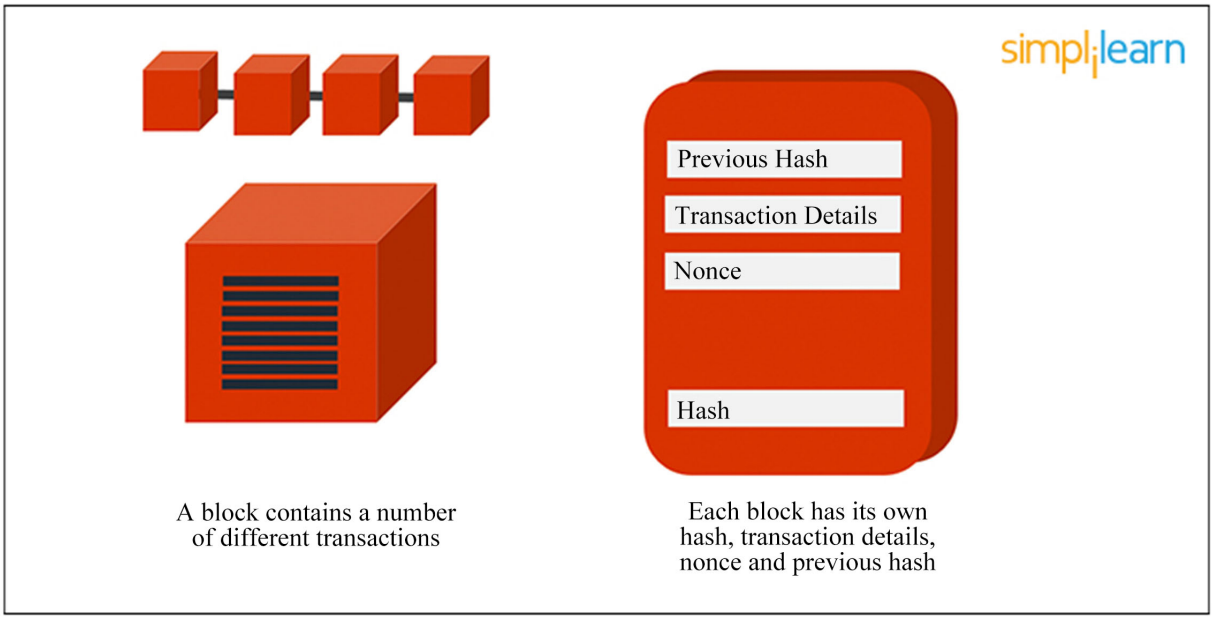

Figure 2. Proof of work in blockchain technology [16].

From Figure 2, it can be seen that every block in a blockchain consists of four headers and those are-

- Previous hash-The previous block is situated at this hash address. Blocks also have a reference to the previous block. This is mentioned in the preceding hash.

- Transaction details-All the transactions details which need to occur are stored in the block. The block is created to store these information.

- Nonce-For separating the block's hash address, a subjective number is given in cryptography that is called a Nonce. This Number can be used only once. Miners adjust this number to make a valid number for the hashing value. With the perfect Nonce the hash value is calculated again which makes the hash more difficult to break.

- Hash address of the block-An output is found for all of above when communicated through a hashing calculation. A 256-digit, 64-character length esteem is contained in that yield. That is what is known as the exceptional "hash address". It is otherwise called the hash address of the block. Figure 3 shows the hashing algorithm used in blockchain.

Utilizing computational calculations, numerous individuals all throughout the planet attempt to sort out the right worth of the hash to fulfill the foreordained condition. At the point when the foreordained condition is fulfilled, the exchange is finished. Basically, it could very well be said that blockchain excavators from one side of the planet to the other to settle a numerical riddle. Whoever settles it initially gets an award.

\subsection{Mining}

The way toward adding conditional subtleties to the current public record is known as mining in blockchain innovation. Mining includes producing the hash of a block exchange, which is hard to manufacture, subsequently guaranteeing the security of the whole blockchain without requiring a focal framework. 


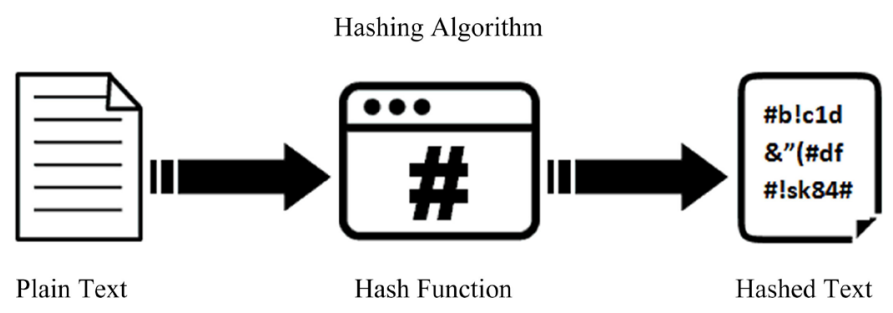

Figure 3. Hashing algorithm used in Blockchain [17].

\subsection{Types of Blockchain}

A public blockchain is a completely decentralized blockchain which can be utilized by anybody with a base asset. The principal motivation behind the open blockchain is to eliminate the middle people and work with distributed exchanges. The basic illustration of public blockchains is Bitcoin, Ethereum, and other digital forms of money, which are straightforwardly accessible to anybody. Every exchange is confirmed by the organization before it is recorded, so they are profoundly successful. Public blockchain is costly and moderate contrasted with private blockchain, however it actually beats the current frameworks utilized for recording.

A Private blockchain is a permission based sort, implying that members need consent from focal position to play out the assignment. It isn't completely decentralized and is constrained by the delegate. Every exchange is confirmed by power before it is recorded. Private blockchain is quicker and less expensive contrasted with public blockchain. It is generally reasonable for corporate business and administration models. It can possibly expand the proficiency and lessening the activity costs. The utilization instance of private blockchain can be web based democratic framework. A sub-class of private blockchain is consortium blockchain which has same attributes as private blockchain, then again, actually it is possessed by a gathering of substance

A hybrid blockchain is a blend of private and public blockchains. It gives a decentralized climate in a private organization. It offers incredible adaptability and authority over the information. It is generally appropriate for exceptionally directed organizations. XinFin is an illustration of half and half blockchain worked by joining Ethereum(public) and Quorum(private). It gives answer for worldwide exchange, account, and inventory network.

\section{Discussion}

Recently, there have been significant changes in banking on account of the Blockchain. As the Blockchain permits untrusted gatherings to concur on the condition of a data set, individuals don't have to depend on agents for an exchange. Blockchain innovation offers monetary types of assistance, for example, instalments, without utilizing any outsider like a bank. Blockchain can give quicker instalments and lower expenses than banks, with the decentralization record for instalments. On open blockchains, protections like stocks, bonds, and elective resources are set. This makes more productive capital business sectors. 
Some of the top benefits of Blockchain in banking are given below:

1) Cost reduction-This is one of the advantages of the Blockchain for banks. Figure 4 shows cost reduction by using blockchain in the banking sector. Most banks are investigating and exploring the use of Blockchain. It was found that Blockchain can reduce up to $70 \%$ cost in central finance reporting. Also can save $50 \%$ cost on business operation. It can also make cost less than half on compliance. It has gone to the consideration of banks that constantly of 2022, Blockchain can permit them to decrease framework costs by up to $\$ 20$ billion. Banks can likewise bring down the exchange costs between bank-to-bank exchanges by utilizing the Blockchain.

2) Faster transactions-These are another top advantage of utilizing Blockchain in banking. Utilizing blockchain technology, exchanges can be made inside the space of seconds, which is quicker than most customary financial strategies. As banks can keep away from agents by utilizing the Blockchain, clients can make exchanges at a faster speed. This will bring about clients and banks ready to finish and handle more exchanges.

3) Improved security-Banks can have better secure exchange data utilizing the assistance of shared records. In the event that blockchain innovation is utilized in banking, exchanges will be quick and the possibility of somebody catching exchange data or redirecting installments will be decreased fundamentally. Figure 5 shows the top security breaches of the $21^{\text {st }}$ century. In the accompanying figure, top information penetrates of the $21^{\text {st }}$ Century is appeared. From the figure, we can see that Among the biggest data breaches, there are many banking or finance company exists. Equifax is one of the largest credit bureaus in the U.S. It generates credit reports and credit scores also gives protection with monitoring and alert. It discovered the data breach on July 29, 2017, where almost 143 million account information was exposed. Over 134 million credit card info was exposed from Heartland Payment Systems Large Banks like JP Morgan Chase also couldn't save themselves from the data breach. Almost 76 million account data was exposed from the bank.

\section{POTENTIAL OUTCOMES OF BLOCKCHAIN IN BANKING}

Global annual cost savings would equate to US\$12 billion

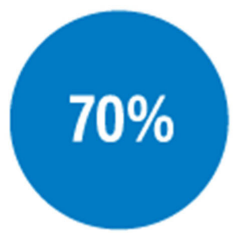

cost savings on central finance reporting

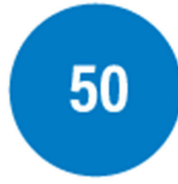

cost savings on business operations

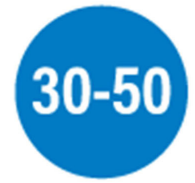

cost savings on compliance

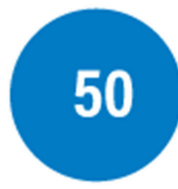

cost savings on centralised operations

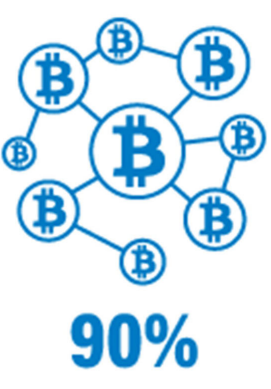

of bankers worldwide say their bank is exploring the use of blockchain

Figure 4. Cost reduction by using Blockchain in the banking sector [18]. 


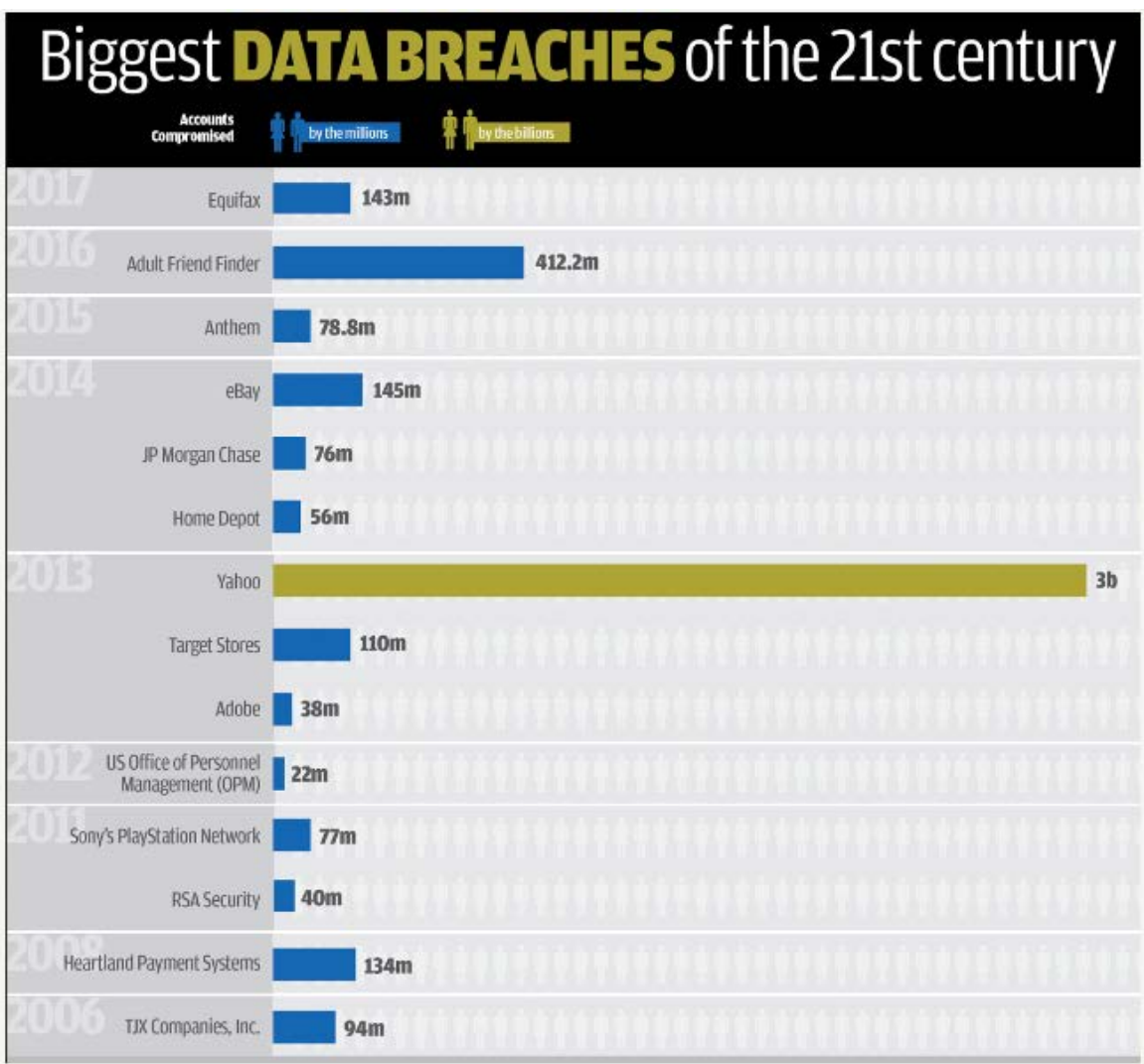

Figure 5. Top security breaches of the $21^{\text {st }}$ Century [19].

The Blockchain offers trust on the grounds that $45 \%$ of monetary mediators are inclined to financial wrongdoing. Across the globe, banking frameworks are intended to work by means of an incorporated data set. Subsequently, they are defenseless against genuine digital assaults because of their numerous marks of disappointment. Actually, every one of them is a programmer who needs to access the framework to break it. When this occurs, misrepresentation is famous if such penetrate isn't seen on schedule. There are two security keys that exist for exchange. Among those keys, a public key is accessible for each utilization, yet the private key is divided among the gatherings of a given exchange. At the point of being affirmed, the data from trade is unchangeable.

4) Improved information quality-Any sort of information can be put away in current blockchain innovation and furthermore permits it to be gotten to adhering to predefined rules and guidelines. The innovation known as savvy contracts naturally confirms and authorizes contracts. By moving financial data into shared records, the data then, at that point, acquires the advantages of the Blockchain.

5) Digital currencies-With the utilization of advanced monetary standards, banks can profit with Blockchain. They are currently ready to acknowledge computerized money to finish an assortment of exchanges. With digital currency, banks will actually want to more effectively clear and settle monetary exchanges quicker and all the more safely. Banks will likewise hope to use compu- 
terized cash as a standard of money later on.

6) Accountability-Due to the presence of accountability in blockchain innovation, banks will actually want to profit by lessening, eliciting extortion, and abuse of organization resources. Banks currently don't need to stress over critical mistakes as exchanges are carefully created. Additionally, they will not be stressed over creating the data. Banks will actually want to precisely deal with exchanges all the more reliably as the Blockchain makes all exchanges simple to check and confirm.

7) Compliance-Banks will likewise profit from the Blockchain with better consistency. They can permit evaluators and government official's admittance to the Blockchain. With this entrance, evaluators and the public authority can see business unfurl with complete straightforwardness. Banks can likewise catch dubious exchange action and smooth out the evaluating interaction. Monetary organizations are presently ready to give computerized data that is not difficult to figure out and save time by examining the interaction.

8) Reconciliation-Banks are additionally profited by utilizing blockchain innovation as Blockchain permits banks to accommodate exchanges all the more without any problem. Exchanges can be followed rapidly, and mistakes can be found very quickly. This gives the advantage to banks of discovering blunders before an exchange is finished. Therefore, they will have a way to fix blunders before they can cause an issue for the organization and their clients.

Blockchain innovation can help take care of current issues worldwide by bringing new arrangements. An outsider won't be needed to make a global installment. Installment records and accounting are self-started, which diminishes operational expenses. The exchanges will be acted in a quicker time. It will make installments simple and straightforward for the client. Blockchain can be utilized to improve on the huge interaction of drafting the Letter of Credit. Once the parties associated with the exchange have their own blockchain network, the data can be shared on a private conveyed record and the understanding should be possible with the savvy contracts. With blockchain innovation, client information can be put away in a square and the square can be shared among the banks. It builds the proficiency of activity and eliminates the dull works. The information put away in blocks is changeless and guarantees that the data is right. This way, once the information is put away, it could very well be utilized by different banks. Blockchain can be utilized to build the effectiveness of exchange and authority protection administrations. On the off chance that the taking part organizations have a typical blockchain stage, the exchange can be performed in an ongoing way with more noteworthy effectiveness and straightforwardness. It could very well be utilized to keep up with the KYC cycle and the third party.

\section{Conclusion}

This review and discussion are planned for the legitimate comprehension of the blockchain innovation's effect on financial framework. Blockchain innovation 
offers the banking industry numerous interesting chances. For observable effects to happen in the financial industry, certain difficulties should be overcome. In any case, notice that new protection laws should be trailed by the financial business for utilizing this innovation. Security laws should be followed for the wellbeing of both people and associations. The financial business is inseparable from tremendous information. Thus, the applicable specialists need to control and direct the entire cycle for the wellbeing of this gigantic measure of information. Blockchain innovation is still developing and numerous new highlights of the blockchain have arisen in the long term. Presently, it may be seen very well that market is overwhelmed by a gathering of huge organizations uncommon in the tech area, where the big four, Amazon, Facebook, Google and Apple overwhelm. In any case, the truth is that nobody owns the rights to the blockchain. Along these lines, if any new start-up needs to utilize the blockchain in their plan of action, they can do so easily and without any problem. Despite the fact that at first blockchain was planned as a data set stage for cryptographic forms of money, yet now this innovation has been demonstrated as quite possibly the most troublesome innovation to the financial business. It is sure that if banking industry doesn't begin to utilize this innovation appropriately, it will deliver them outdated.

\section{Acknowledgements}

The authors would like to give special thanks to the authorities and the Department of Electrical and Computer Engineering of North South University for giving us the resources and facilities to do this research.

\section{Conflicts of Interest}

The authors declare no conflicts of interest regarding the publication of this paper.

\section{References}

[1] Cointelegraph (2021) Cointelegraph.com. https://cointelegraph.com/bitcoin-for-beginners/how-blockchain-technology-works -guide-for-beginners

[2] Hu, T. and Oost, M.V. (2017) Fueled.com. https://fueled.com/blog/how-blockchain-is-solving-the-finance-industrys-biggest-p rob$\underline{\text { lems/?fbclid=IwAR1rmdXdLKdKffmMyu9jT1yKQOavXwwnVtq4KDXlHpz8tVXrI }}$ vdRd1OgEAA

[3] Vuckovic, N. (2020) Theblockbox.io. https://theblockbox.io/services/

[4] Eyal, I. (2017) Blockchain Technology: Transforming Libertarian Cryptocurrency Dreams to Finance and Banking Realities. Computer, 50, 38-49. https://doi.org/10.1109/MC.2017.3571042

[5] Popova, N.A. and Butakova, N.G. (2019) Research of a Possibility of Using Blockchain Technology without Tokens to Protect Banking Transactions. 2019 IEEE Conference of Russian Young Researchers in Electrical and Electronic Engineering (EIConRus), Saint Petersbugh and Moscow, 28-31 January 2019, 1764-1768. 
https://doi.org/10.1109/EIConRus.2019.8657279

[6] Cocco, L., Pinna, A. and Marchesi, M. (2017) Banking on Blockchain: Costs Savings Thanks to the Blockchain Technology. Future Internet, 9, 25. https://doi.org/10.3390/fi9030025

[7] Harris, W.L. and Wonglimpiyarat, J. (2019) Blockchain Platform and Future Bank Competition. Foresight, 21, 625-639. https://doi.org/10.1108/FS-12-2018-0113

[8] Wu, B. and Duan, T. (2019) The Advantages of Blockchain Technology in Commercial Bank Operation and Management. Proceedings of the 2019 4th International Conference on Machine Learning Technologies, Nanchang, 21-23 June 2019, 83-87. https://doi.org/10.1145/3340997.3341009

[9] Dozier, P.D. and Montgomery, T.A. (2019) Banking on Blockchain: An Evaluation of Innovation Decision Making. IEEE Transactions on Engineering Management, 67, 1129-1141. https://doi.org/10.1109/TEM.2019.2948142

[10] Li, L., Sy, M. and McMurray, A. (2018) Blockchain Innovation and Its Impact on Business Banking Operations. Advances in Parallel Computing, 29, 583-598.

[11] Arantes, G.M., D’Almeida, J.N., Onodera, M.T., Moreno, S.M.D.B.M. and Almeida, V.D.R.S. (2018) Improving the Process of Lending, Monitoring and Evaluating through Blockchain Technologies: An Application of Blockchain in the Brazilian Development Bank (BNDES). 2018 IEEE International Conference on Internet of Things (iThings) and IEEE Green Computing and Communications (GreenCom) and IEEE Cyber, Physical and Social Computing (CPSCom) and IEEE Smart Data (SmartData), Halifax, 30 July-3 August 2018, 1181-1188.

https://doi.org/10.1109/Cybermatics_2018.2018.00211

[12] Gebert, M. (2017) Application of Blockchain Technology in Crowdfunding. New European, 18.

https://www.researchgate.net/publication/318307115_APPLICATION_OF_BLOCK CHAIN_TECHNOLOGY_IN_CROWDFUNDING

[13] Charles, G., Jumamil, A. and Aranyawat, P. (2017) Blockchain and Financial Inclusion: The Role Blockchain Technology Can Play in Accelerating Financial Inclusion. Georgetown University Press, Washington.

[14] Guo, Y. and Liang, C. (2016) Blockchain Application and Outlook in the Banking Industry. Financial Innovation, 2, Article No. 24.

https://doi.org/10.1186/s40854-016-0034-9

[15] Euromoney (2020). Euromoney.com.

https://www.euromoney.com/learning/blockchain-explained/how-transactions-getinto-the-blockchain?fbclid=IwAR1UVAF812J-K70opTQbnM_jq8HJLyANJll_Tr4zGz 6ewTR_Sii7XEX7dvw

[16] Simplilearn (2020) Simplilearn.com. https://www.simplilearn.com/tutorials/blockchain-tutorial/blockchain-technology

[17] Network Encyclopedia (2020). Networkencyclopedia.com. https://networkencyclopedia.com/hashing-algorithm/

[18] Sharma, A. (2018) Blockchain to Boost Regional Banks' Efficiency and Cut Costs. https://www.thenationalnews.com/business/technology/blockchain-to-boost-region al-banks-efficiency-and-cut-costs- 1.765312

[19] Proche (2018) The 17 Biggest Data Breaches of the 21st Century. https://www.theproche.com/2018/05/08/the-17-biggest-data-breaches-of-the-21st-c entury/ 